\title{
Editorial
}

\section{Breeding Science Special Issue: Triticeae}

The Sixth International Triticeae Symposium (6th ITS) took place in Kyoto (Japan) between May 31 and June 5, 2009. The Triticeae tribe includes the majority of the world's most important temperate cereal crops, in particular bread and durum wheat, barley, triticale and rye. The aim of the symposium was to provide a platform where grass systematists, ecologists, gene bank curators and cereal breeders, geneticists, pathologists, molecular biologists and genome researchers could meet and interact with one another, with a particular focus on the Triticeae. In all, 118 participants attended the symposium, coming from 20 different countries, namely Australia, Azerbaijan, Canada, China, Czech Republic, Germany, Georgia, Iran, Italy, Japan, Kazakhstan, Mexico, Poland, Russia, Slovak Republic, Spain, Sweden, Turkey, the UK and the USA. The scientific program was arranged into four sessions: "systematics and phylogeny", "domestication and evolution", "biodiversity and genetic resources" and "genomics and breeding"; these were delivered in the form of 48 oral and 50 poster presentations. A record of the symposium (program and abstracts) is available online at http://www.shigen.nig.ac.jp/ewis/article/ issuePage.do? issue $\mathrm{No}=108$.

The local organizing committee of 6th ITS agreed at a Japanese Society of Breeding (JSB) steering committee meeting, held at the University of Tokyo on 19 September 2008 , to publish the proceedings of the symposium as a special issue of Breeding Science (BS). BS was founded in 1951 , already 59 years ago, but this was to be the first special issue the journal has ever produced. The National Institute of Agrobiological Science (NIAS) granted financial support for the production of the special issue on 12 March 2009, and both JSB and Ministry of Education, Science, Sports and Culture, Japan later added their support (on 27 March 2009 and 2 April 2009, respectively). The idea was well received, since full versions of all papers published in BS are freely available online at http://www.nacos.com/jsb/. As a result, a permanent record of the 6th ITS proceedings is now available to all. A print copy of the proceedings will also be offered to both the $\sim 2000$ members of the Japanese Society of Breeding, and to all the participants of the 6th ITS.
All the oral presenters and a number of selected poster presenters were encouraged to contribute a manuscript to the BS special issue. All the manuscripts received have been peer-reviewed by a number of local and international scientists. We take the opportunity therefore to particularly thank our colleagues M. Abiko, N. Asakura, M. Barkworth, F. Blattner, T. Fujiwara, J.S. Heslop-Harrison, K. Hori, S. Jakob, K. Kakeda, B. Kilian, M. Kishii, A. Kleinhofs, T. Koba, J. Kumlehn, S. Larson, Bao-Rong Lu, Mingcheng Luo, Y. Mukai, K. Murai, S. Nakamura, S. Nasuda, H. Nishida, T. Ogawa, Y. Ogihara, S. Ohta, H. Özkan, G. Petersen, M. Pourkheirandish, S. Sakuma, B. Salomon, K. Sato, T. Schnurbusch, Y. Shavrukov, G. Sun, S. Taketa, S. Takumi, T. Terachi, H. Tsujimoto, T. Tsukiyama, Y. Turuspekov, K. Yonezawa, K. Yoshida and Y.-H. Zhou for their willing co-operation in this process. Their constructive comments have been invaluable in helping us to improve the quality of the material making up the special issue. Finally, BS decided to accept 12 review papers, 17 research papers, and one short communication for publication in the special issue. The peer review process began on 21 July 2009 and the last acceptance decision was made on 18 November 2009. The editors working on the special issue were H. Tsujimoto, T. Terachi, D. Xu, N. Mori, M. Iwanaga, A. Kleinhofs, N. Stein and T. Komatsuda. Technical editing was managed by F. Taguchi-Shiobara.

The local organizing committee members were T. Kawahara, K. Sato, K. Kakeda, M. Kishii, T. Komatsuda, S. Takumi, H. Tsujimoto, T. Sasanuma, T. Ban and H. Miura; and the international organizing committee members were R. von Bothmer, M. Barkworth, B.S. Bushman, V. Holubec, T. Kawahara, H. Knüpffer and K. Sato. The symposium was held under the joint auspices of the local and international organizing committees, and NIAS, with infrastructure provided by Kyoto University.

Takao Komatsuda Managing Editor National Institute of Agrobiological Sciences 


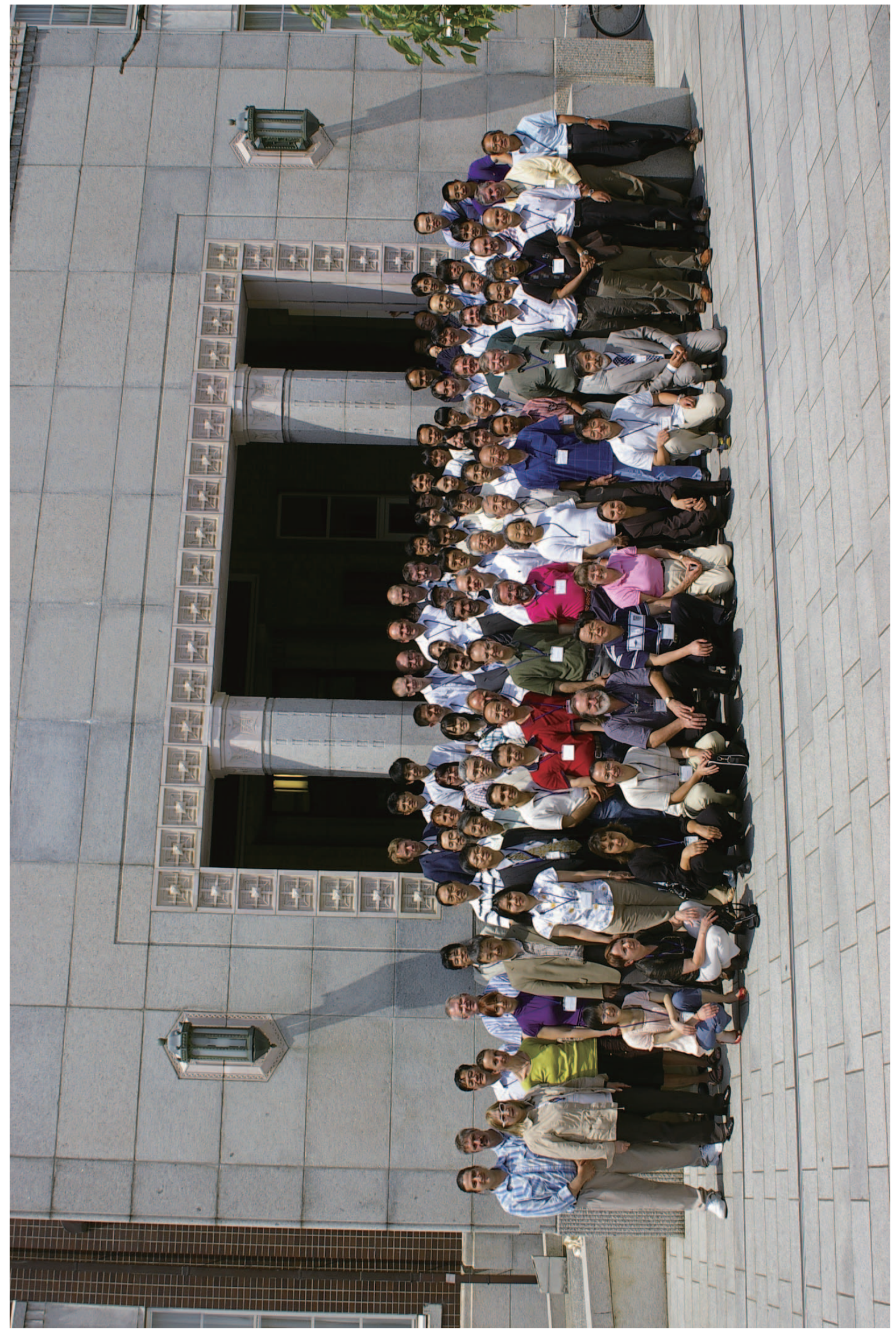

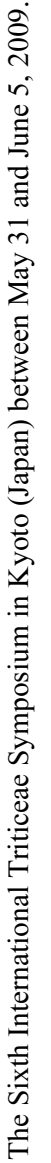

